\title{
Bypassing and tightening of an underground water retention system in permeable karst: case study of the hydropower plant (HPP) Bribin, Indonesia
}

\author{
Peter Kudella $^{1} \cdot$ Iryna Loges $^{1} \cdot$ Thomas Mutschler $^{2} \cdot$ Elisabeth Eiche $^{2} \cdot$ \\ Julia Ruppert ${ }^{2}$ Thomas Neumann ${ }^{2}$
}

Received: 18 January 2016/ Accepted: 11 May 2016/Published online: 30 May 2016

(c) The Author(s) 2016. This article is published with open access at Springerlink.com

\begin{abstract}
In the framework of the Integrated Water Resources Management (IWRM) joint research project in the karst area of Gunung Kidul, Province of Yogyakarta Special Region on the Java Island, Indonesia, an underground hydropower driven water extraction facility in the cave "Bribin" was developed using pump-as-turbine-driven systems for freshwater supply of the rural area. As numerous other caves in the Gunung Kidul area, Bribin is part of a ramified system of all-season water-bearing subterraneous rivers and natural caves in karstic limestone. The elliptic cross section of the cave was completely closed with a concrete barrage, thus creating a year-round underground retention volume with an operational storage level of approx. $15 \mathrm{~m}$. This contribution highlights the geotechnical and geohydraulic challenges handled within the sub-project "Short-time and long-time behaviour of karst rock surrounding pressure-bearing underground water-retaining structures". One key to the feasibility of an artificial water retention scheme in a natural cave is to ensure the mechanical stability of the cave roof and sidewalls. The necessary geotechnical investigations are described. Another key to the effectiveness of such a water retention concept is the control and minimization of "lost" seepage water bypassing the barrage structure through the
\end{abstract}

Peter Kudella

Peter.kudella@kit.edu

1 Institute for Soil Mechanics and Rock Mechanics, Karlsruhe Institute of Technology, Engler-Bunte-Ring 14, 76131 Karlsruhe, Germany

2 Institute for Applied Geosciences, Karlsruhe Institute of Technology, Adenauerring 20b, 76131 Karlsruhe, Germany karst rock mass. Measures to monitor and to explain the seepage phenomena are presented as well as grouting efforts to minimize them. The limitations of improving the overall tightness will be discussed. Interpretation includes the use of analytical and numerical methods.

Keywords Seepage Monitoring · Borehole camera . Grouting $\cdot$ Numeric Modelling $\cdot$ Permeability

\section{Concept of the underground hydropower plant Bribin}

About $20 \%$ of the continental surface of the earth is covered with karstified limestone and about $25 \%$ of the drinking water comes from karst aquifers. Karstified rock exhibits a very complex behaviour with regard to both mechanical and hydraulic aspects. Foundations and water tight constructions as dams need sophisticated procedures. The installation of an underground hydropower plant (HPP) at Gua Bribin (Gua: the Indonesian word for cave) serves as a demonstration object for micro-hydro power application in rural karst areas where a seasonal shortage of water as well as a shortage of renewable energy could be overcome by utilizing the subsurface karst water resources. The concept of the underground HPP Bribin, including the implementation, operation and monitoring measures, is discussed among others in Nestmann et al. (2012). Here, the complete flow section of a karst cave is closed by a concrete barrage. A dry working platform accessible by a vertical shaft hosts a flood relief system and 5 water conveying modules consisting of PAT, gearbox and highpressure feed pump delivering a part of the water yield to a reservoir elevated by $220 \mathrm{~m}$. Figure 1 gives an overview of the system. 


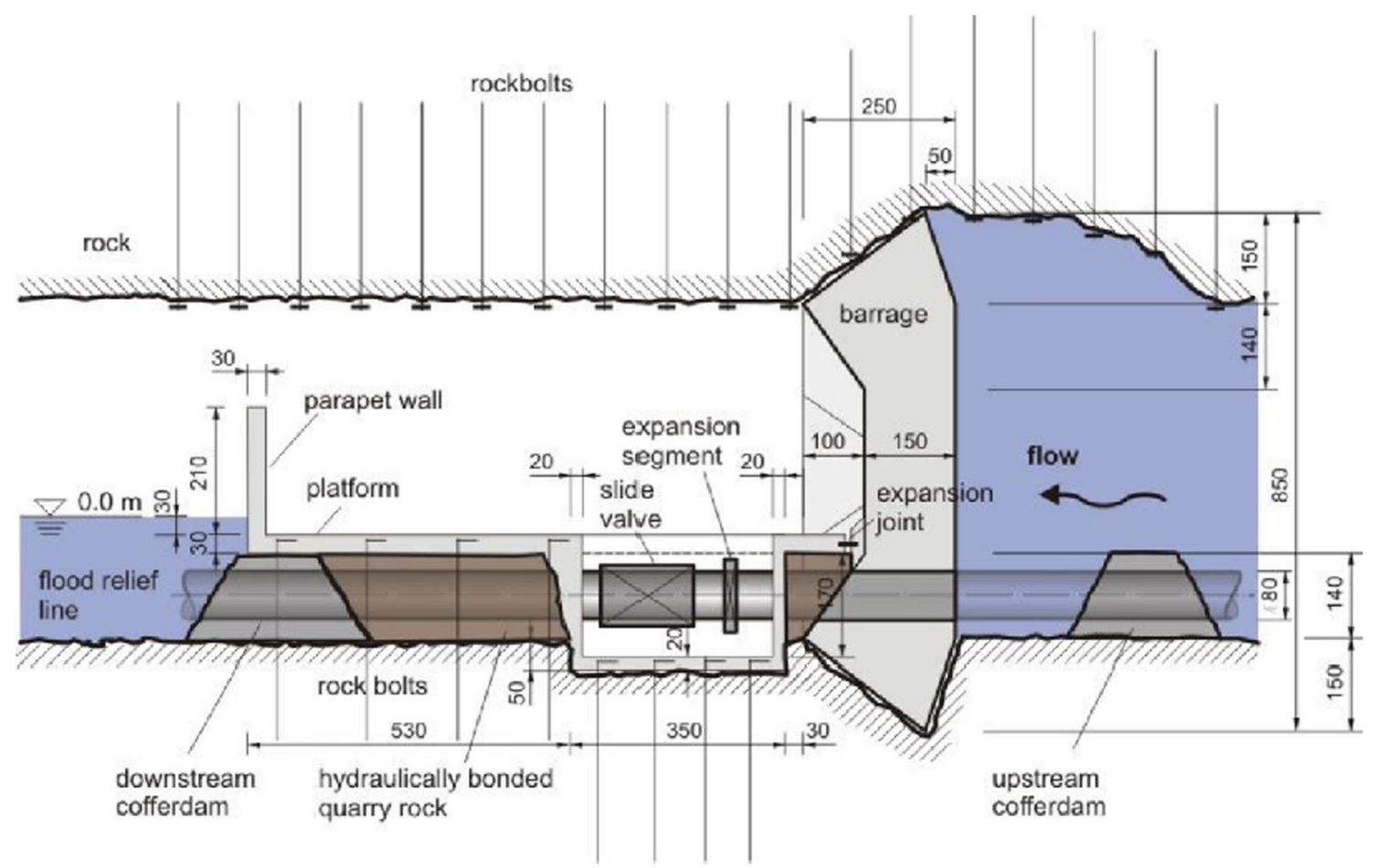

Fig. 1 Longitudinal section of the plant with structural elements and functional HPP components (Breiner et al. 2011); the vertical shaft, the water conveying modules and the piping system are not shown

\section{Research objectives}

Besides a demonstration object for comprehensive capacity development for the Indonesian partners, the leading idea was the scientific use of Gua Bribin as a "laboratory cave" for a micro-hydro power plant in a karst environment. This publication will specifically discuss the geotechnical aspect of the activities which comprised:

- Contribution to the establishment of a monitoring system for storage level, seepage quantities and deformations of the barrage and the surrounding limestone rock. This monitoring should allow the evaluation of the plant's safety and serviceability based on the criteria for critical states developed during the monitored operational period.

- Comprehensive and representative modelling of cave rock mechanics and geohydraulics based on data gained during field explorations, in situ tests, endoscopic investigations with borehole tools as well as by numerical modelling.

- Investigation and description of the rock mass with regard to size, distribution and filling of voids and fractures and the related erosion, permeability, seepage and bypassing to ensure the rock mass integrity against hydraulic breakthroughs.
- Reduction of bypassing seepage and stabilization of karst hose fillings if required, using adapted injection technologies and materials.

From the geo-engineering point of view, all activities aimed to guarantee the stability of the barrage foundation, the sidewalls and roof of the cave, including the buoyancy of the HPP platform and, as far as possible, the life-time serviceability of the underground HPP.

\section{Preliminary investigations}

Rock mass stability was addressed at an early planning state already. A vertical $100 \mathrm{~m}$ deep borehole had been drilled from the surface down to the later construction site as a preliminary investigation for the access shaft. In this borehole, falling head slug tests above the cave revealed a permeability varying over three orders of magnitude from $2 \times 10^{-8}$ to $5 \times 10^{-6} \mathrm{~m} / \mathrm{s}$, due to intense variability of the more or less porous limestone (Fig. 2).

Investigation boreholes TB 01-TB 04 (length $10 \mathrm{~m}$ ) were cored from the machinery platform into roof, floor and sidewalls of the cave (Fig. 3). These drillings were arranged in a vertical plane in the cross section where the barrage later was built. While the rock quality in TB 01 


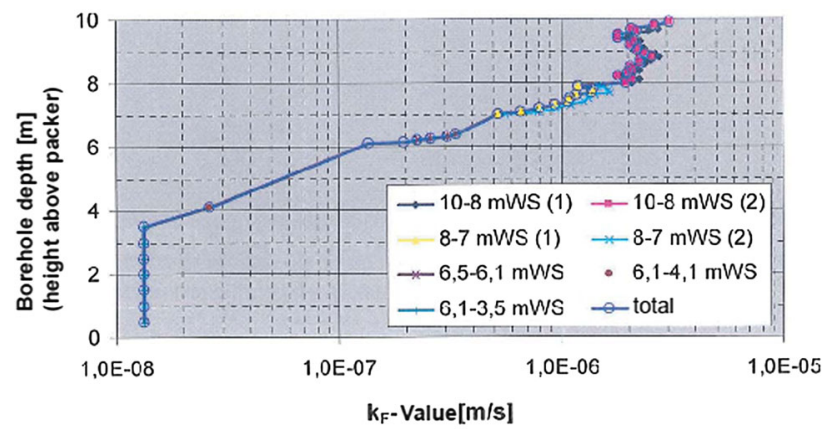

Fig. 2 Permeabilities measured above cave roof
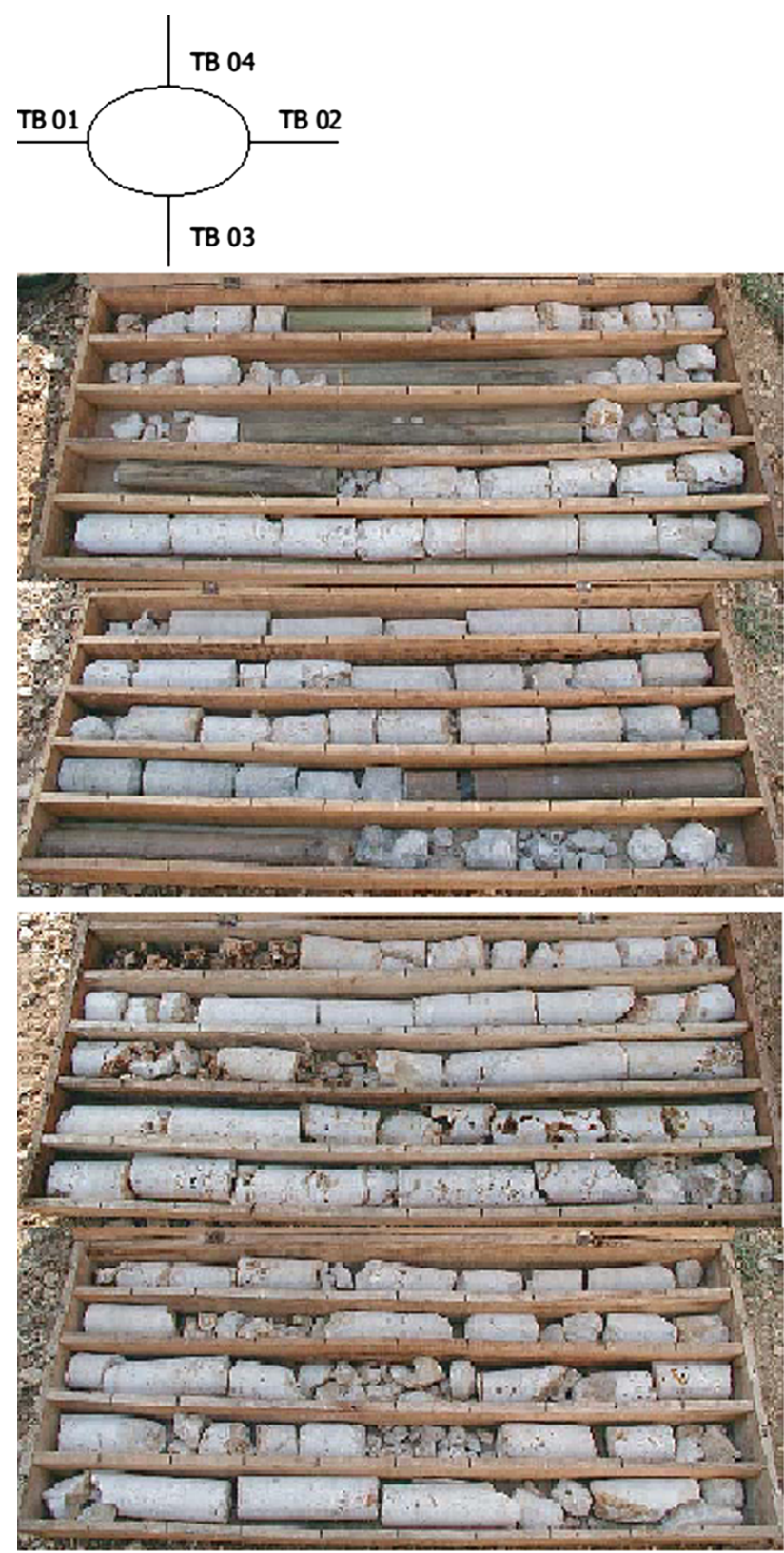

Fig. 3 Borehole orientation at the barrage site and cores from TB03 (floor) and TB04 (roof) in comparison and TB 04 proved to be sufficient $(\mathrm{RQD}=49)$, boreholes TB 02 and TB 03 in the floor showed very poor conditions $(\mathrm{RQD}=28)$. These findings were confirmed by four supplementary vertical boreholes TB 03-1 to TB 03-4 in the floor (next to TB 03). At that time, these results gave reasons to concerns regarding the stability and permeability of the right cave wall and the floor.

These concerns were qualified later by Lugeon tests in the boreholes showing permeabilities of $6 \times 10^{-7}$ to $1.2 \times 10^{-5} \mathrm{~m} / \mathrm{s}$ (based on a hydraulic radius of $1 \mathrm{~m}$; values result 2.4 times higher with an assumed radius of $100 \mathrm{~m}$ ). The results confirmed the higher void ratio at drillings TB 02 and TB 03, but not to an extent where the feasibility of the general concept had to be questioned (Müller et al. 2008). So the designers responded with additional measures to improve the barrage foundation, which will be explained later.

Compared to the exclusively calcitic reef limestone encountered during the drilling of the access shaft, the redbrown, yellow and white facies at the cave walls also contained kaolinites and smectites as typical tropical weathering products. Whether the clayey fillings in open cracks and voids were products of in situ weathering or of subsequent sedimentation could not be decided.

Laboratory tests on cores of the reef limestone showed porosities between 5 and $20 \%$, bulk densities between 2.2 and $2.6 \mathrm{~g} / \mathrm{cm}^{3}$, uniaxial compressive strengths from 10 to $80 \mathrm{MPa}$ and deformation moduli between 2 and $10 \mathrm{GPa}$. Multi-stage triaxial tests resulted in friction angles of $49-56^{\circ}$ with a corresponding cohesion of 1.3-8.5 MPa.

The inspection of Gua Bribin in October 2005 (Mutschler and Berner 2005) summarizes the geotechnical situation based on the observation of the uncovered rock surface (excavation for the concrete barrage) and further tests. It defines four homogeneous zones (Table 1; Fig. 4):

Following a re-evaluation of the cave's stability after a devastating earthquake in 2006 ["Report on Inspection of "Bribin"-Project and "Seropan"-Project June 5-13, 2007", in (Kudella and Loges 2014)], the barrage construction works were finalized in 2008 following the original design. In the upper third of the barrage structure, the instable breccia had been excavated spaciously and replaced by concrete seals.

The cave roof above the machinery platform was secured using $100 \mathrm{kN}$ rock nails $\left(0.5\right.$ nails $\left./ \mathrm{m}^{2}\right)$ of $4 \mathrm{~m}$ length. Further nails in the floor provide additional safety for the platform and the sliding valve chamber (see Figs. 1, 7) against buoyancy. Below the barrage's base, a stiffening "shoe plate" on three rows of short micropiles was provided, improving the underlying weathered rock's resistance against mechanic and hydraulic impact (Mutschler and Triantafyllidis 2009). An alternative concept of stepwise investigation and strengthening by soil replacement, 
Table 1 Rock mass zonation and properties

\begin{tabular}{|c|c|c|c|c|}
\hline Zone description & $\begin{array}{l}\text { Massive banked reef } \\
\text { limestone }\end{array}$ & $\begin{array}{l}\text { Porous and cavernous reef } \\
\text { limestone }\end{array}$ & $\begin{array}{l}\text { Broken and jointed cavernous } \\
\text { reef limestone }\end{array}$ & $\begin{array}{l}\text { Breccia (limestone fragments in } \\
\text { clay matrix) }\end{array}$ \\
\hline Location & $\begin{array}{l}\text { Roof, } 1-2 \mathrm{~m} \text { center } \\
\text { walls }\end{array}$ & $1-2 \mathrm{~m}$ lower walls & $1 \mathrm{~m}$ in floor & $1.5-2 \mathrm{~m}$ upper walls \\
\hline Strength & $\begin{array}{l}\text { High: } \\
c>5 \mathrm{MPa} \\
\varphi>40^{\circ}\end{array}$ & $\begin{array}{l}\text { Variable: } \\
1<c<5 \mathrm{MPa} \\
30^{\circ}<\varphi<40^{\circ}\end{array}$ & Fluctuating & Low \\
\hline Deformability & $\begin{array}{l}\text { Low: } \\
1<E_{\mathrm{v}}<5 \mathrm{GPa}\end{array}$ & $\begin{array}{l}\text { Low: } \\
500<E_{\mathrm{v}}<1000 \mathrm{MPa}\end{array}$ & $\begin{array}{l}\text { Variable: } \\
5<E_{\mathrm{v}}<50 \mathrm{MPa}\end{array}$ & $\begin{array}{l}\text { High: } \\
E_{\mathrm{v}}<50 \mathrm{MPa}\end{array}$ \\
\hline Permeability & $\begin{array}{l}\text { Low: } \\
10^{-6}<k<10^{-3} \mathrm{~m} / \mathrm{s}\end{array}$ & $\begin{array}{l}\text { Variable: } 10^{-6}< \\
\quad k<10^{-2} \mathrm{~m} / \mathrm{s}\end{array}$ & $\begin{array}{l}\text { High: } \\
10^{-4}<k<10^{-2} \mathrm{~m} / \mathrm{s}\end{array}$ & $\begin{array}{l}\text { Very Low: } \\
10^{-8}<k<10^{-6} \mathrm{~m} / \mathrm{s}\end{array}$ \\
\hline Groutability & Very limited & Limited & Fair & None \\
\hline $\begin{array}{l}\text { Foundation/stability } \\
\text { conditions }\end{array}$ & Good & Fair & Poor & Very poor \\
\hline Sealing properties & Good & Poor & Poor & $\begin{array}{l}\text { Good, but danger of break } \\
\text { through }\end{array}$ \\
\hline
\end{tabular}

Fig. 4 Appearance of rock mass zones: Massive (top left), cavernous (top right), broken (bottom left) and breccious limestone (bottom right)
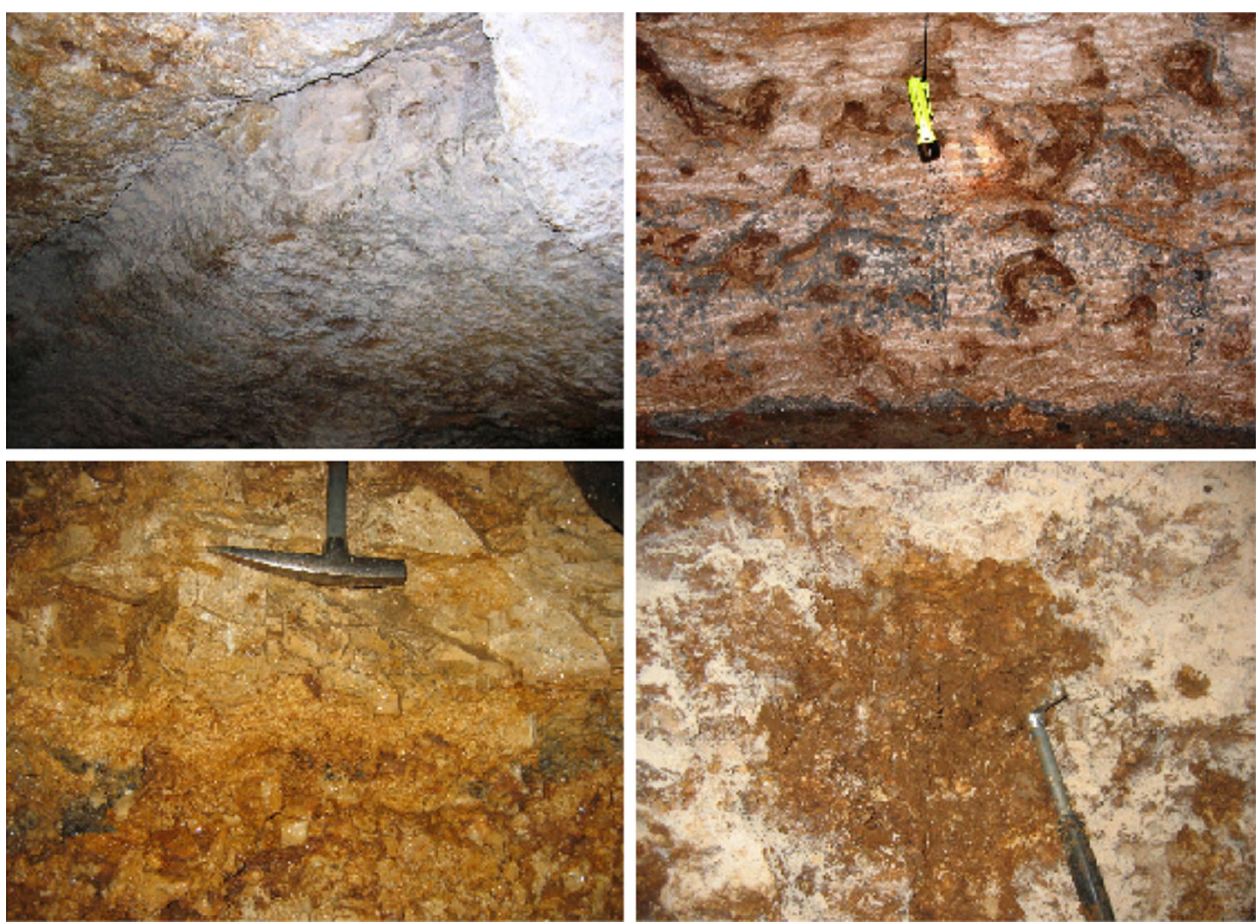

usage of longer piles and contact grouting, was also discussed, but not realized by the Indonesian partners.

\section{Monitoring system}

The Bribin deformation monitoring system is based on the concept of repeated convergence monitoring (Fig. 5). Between 8 points of a vertical plane and 4 points of a horizontal plane, 14 measuring tracks had been defined. It was regarded as sufficient that at least 8 of these tracks could still be controlled after the installation of the HPP's machines and pipes (Mutschler and Triantafyllidis 2009).

About 20 repeated measurements over 3 years of operation showed no significant length difference. Most deformations were shortenings of the cave's width. It seems that the horizontal distances are converging slightly more than the vertical ones due to water pressures in the cave walls acting on the sidewalls of the platform. The maximum convergence of $1.7 \mathrm{~mm}$ was monitored in horizontal direction between the sidewalls. It is attributed to water pressures acting predominantly from the sides and 


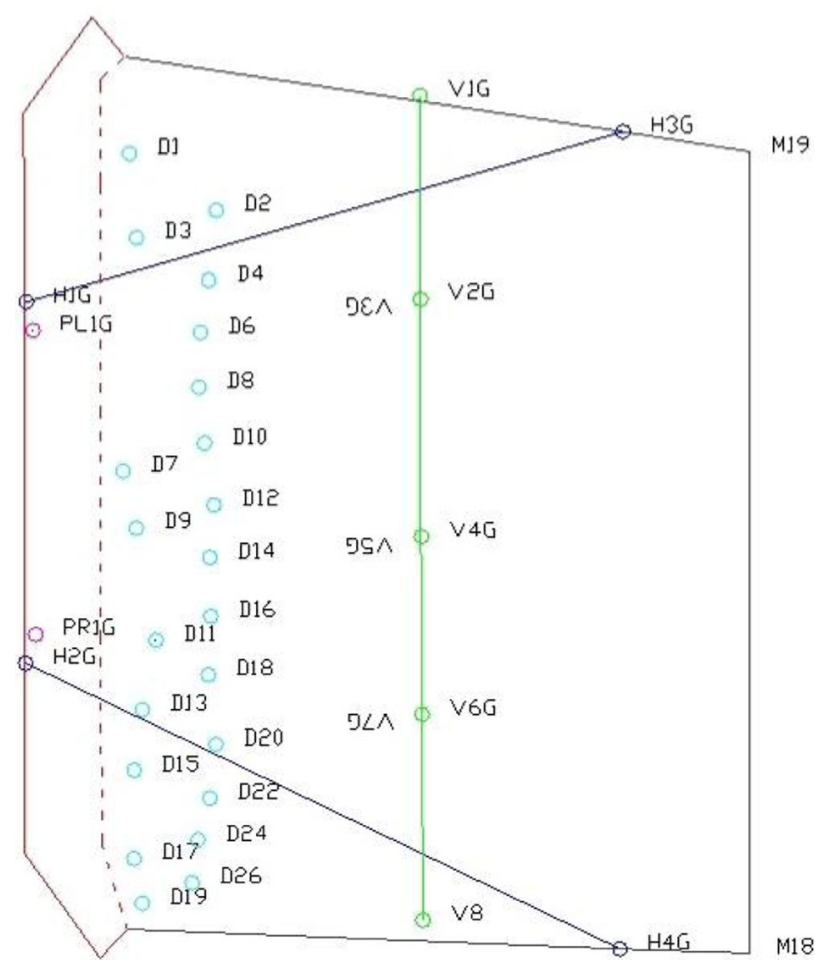

Fig. 5 Convergence measurement: measuring tracks in plan view

considered to be uncritical. The barrage structure itself was also controlled for rotational deformation components using two plummets. A systematic and continuous deformation monitoring was recommended to the local staff as well as to the operating authorities' scientific partners from local University Gadjah Mada, Yogyakarta.

Seepage measurements were another important component of the monitoring concept. Water seeped from the 22 boreholes located in the roof in two rows behind the barrage as a drainage curtain and from 7 further spots at the cave wall (Fig. 6). Before the implementation of the automated monitoring system, which is explained later, the seepage water was collected manually from the single spots and attributed to either the right, left or central part of the cave (Fig. 6). Reservoir filling tests to hydraulic heads of up to $16 \mathrm{~m}$ were accompanied by such manual readings once or several times a day. In some cases, hydraulic heads of up to $20 \mathrm{~m}$ were reached due to simultaneous floods.

For heads below $6 \mathrm{~m}$, typically only 6 drainage spots were water-bearing. Higher hydraulic heads "triggered" more and more leaks to start seeping.

Manual measurements have been repeated during five periods between 2008 and 2011 to quantify the success of grouting measures described later. Thereafter, an automated monitoring system had been put into effect, which is explained later, too. In addition to that, the operating

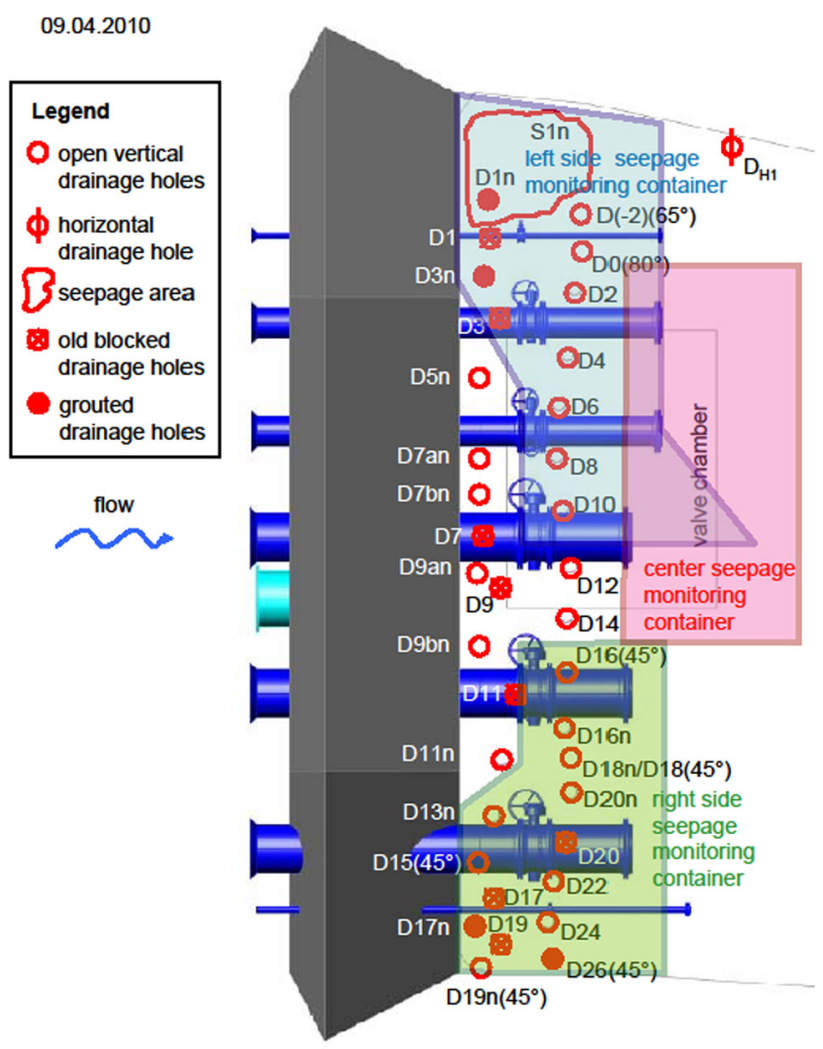

Fig. 6 Plan view of monitored drainage pipes and seepage spots in the downstream cave roof

personnel were assigned to continue the manual measurements to enable an analysis of the seepage's spatial distribution.

Undercurrent and water pressure built-up below the cave floor and the machinery platform have always been questions of interest. A vertical borehole from the sliding valve chamber (a recess in the platform) was equipped with a standpipe and connected to a manometer. Indeed it's hydraulic connection to the limestone layers and their permeability was not clear as well as the exact position and function of drainage pipes which had been placed in the rockfill below the platform. As long as the standpipe was monitored, measured water pressures never reached a critical value in terms of buoyancy risks. Surprisingly, the pressures seemed to be independent from the hydraulic head inside the reservoir. This matches with the observations made in August 2011 when indicators of a flow passing underneath the platform were checked. Here, two methods were used. First, a fibre fixed to a bamboo rod was inserted at several locations downstream of the parapet wall (see Fig. 1) during a downtime of the machinery, but with a storage level of $11 \mathrm{~m}$. There was no indication of a directed flow detected. Under the suction pipe of PAT 2 (second from the left in flow direction), the outlet of a 
drainage pipe is located. To indicate turbulences caused by a potential water outlet, a dyeing test with potassium manganate was made. The lumped addition of the violet colouration formed a cloud which enlarged only very slowly, thus giving again no indication of a concentrated flow passing underneath the platform. The installation of three lines of micropiles (Fig. 7) in the foundation zone below the barrage aims to improve both the structural safety and the permeability behaviour of the underlying beds.

\section{Additional laboratory tests}

These tests focussed on the clayey-silty fillings, encountered as sediments at the cave floor, in karst cavities and fractures. They can be described as a fine-grained sludge containing clay and limestone nuggets of $2-5 \mathrm{~mm}$ side length. Their permeability is low, but also their potential resistance against dislocation and erosion (Mutschler and Triantafyllidis 2009). Grain size distribution and Atterberg limits of sludge from different locations were tested following a minor "hydraulic breakthrough" event identified by the manual seepage measurements (Table 2; Fig. 8).

\section{Borehole scanning}

Drilling of boreholes was accompanied by endoscopic analyses from the beginning of the planning and implementation process. This technology is a recommended practice to identify cracks, joints and cavities in boreholes on a qualitative level. Initially, the observation depth was

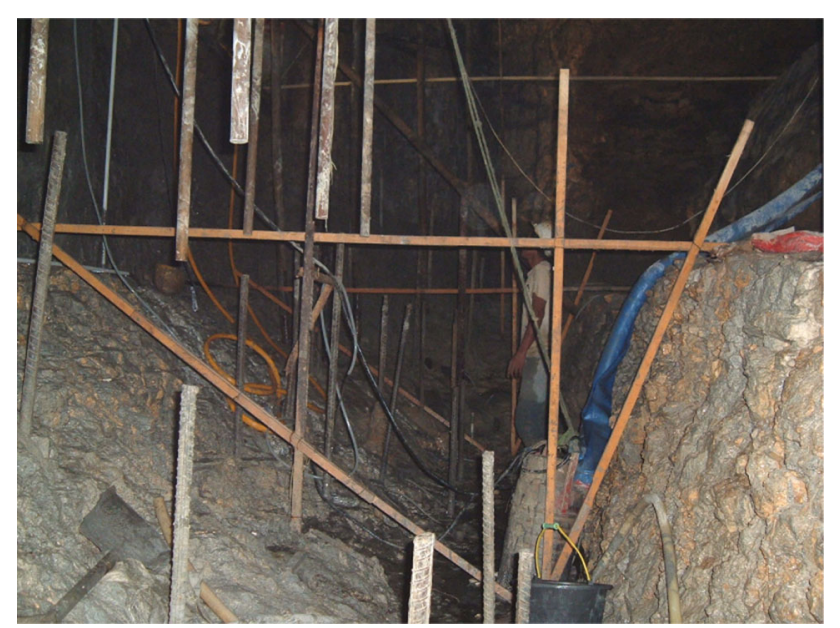

Fig. 7 V-shaped excavation zone below the barrage with three lines of micropiles limited to $4 \mathrm{~m}$ using a bar endoscope. A later utilized flexible endoscope extended the reach to $20 \mathrm{~m}$.

In cooperation with the industrial partner GIF (Geotechnisches Ingenieurbüro Prof. Fecker \& Partner GmbH, Ettlingen, Germany, sub-project 15 of the IWRM joint research project), a borehole scan had been carried out in Gua Bribin and in another karst cave, using a borehole camera combining a rotatable optical sensor with a camera. It produces a video stream of a borehole wall, which enables to measure gap openings and crack orientations and to survey the geometry of cavities.

This borehole camera scanned the $100 \mathrm{~m}$ deep vertical exploration borehole from the surface and two of the $10 \mathrm{~m}$ deep investigation boreholes TB 01 (horizontal on the left side) and TB 04 (overhead) at the barrage site (Fig. 9). For reporting, a simple but consistent borehole description was used displaying the number of bedding joints per metre as a red bar and the diametre of borehole breakouts and cut karst cavities as a green bar (Fig. 10).

Karstification was found in the $100 \mathrm{~m}$ deep borehole continuously between 30 and $95 \mathrm{~m}$ below surface, and concentrated in the depth zones 43-48, 52-53, 56-59, 61-81 and 89-94 m. The rock mass is pervasively jointed, mechanically damaged and weathered. Karst erosion usually starts from horizontal bedding joints and their intersection with vertical fractures.

In borehole TB 04, the automated record of the insertion depth (using a mechanical scrolling device) did not work correctly due to the overhead condition. Therefore, the actual height position of the video camera had to be reconstructed in a complex procedure, comparing snapshot similarities of the records during insertion and pull-out. Nevertheless, a residual uncertainty of the reconstructed positions remained.

Karst cavities were encountered in depths of 5-7 m (above cave), while the first $5 \mathrm{~m}$ above the roof was confirmed (as already observed by earlier endoscopic analyses) as competent, void-free reef limestone formations. This confirms the assumption of a sufficient stability of the cave roof. Horizontal borehole TB 01 runs in a massive limestone layer with only little fissures and shows no karstification.

The results of the camera inspections accomplished in 2014 (Reported in (Kudella and Loges 2014)) can be summarized as follows:

- The planned fixation of various tubes in the cave roof (not shown in Fig. 1) using relatively short (1-2 m) rock anchors is safe and efficient.

- Due to the small crack openings in the limestone inside the cave roof, the rock mass reaction against static load changes is stiff, resulting in small convergence. 
Table 2 Properties of clayey-silty void fillings

\begin{tabular}{|c|c|c|c|c|}
\hline Origin & Karst hose near shaft & "Sludge cave" & Drainage pipe D26 & Reference sample from Gua Seropan \\
\hline Clay content, $(\%)$ & 80 & 71 & 75 & 75 \\
\hline Liquid limit, $(\%)$ & 119 & & & 55 \\
\hline Plastic limit, (\%) & 41 & & & 32 \\
\hline Shrinkage limit, $(\%)$ & & & & 21 \\
\hline Consistency & 0.035 & & & 0.138 \\
\hline
\end{tabular}

Fig. 8 Sludge sedimentation (left) and desiccation test (right)
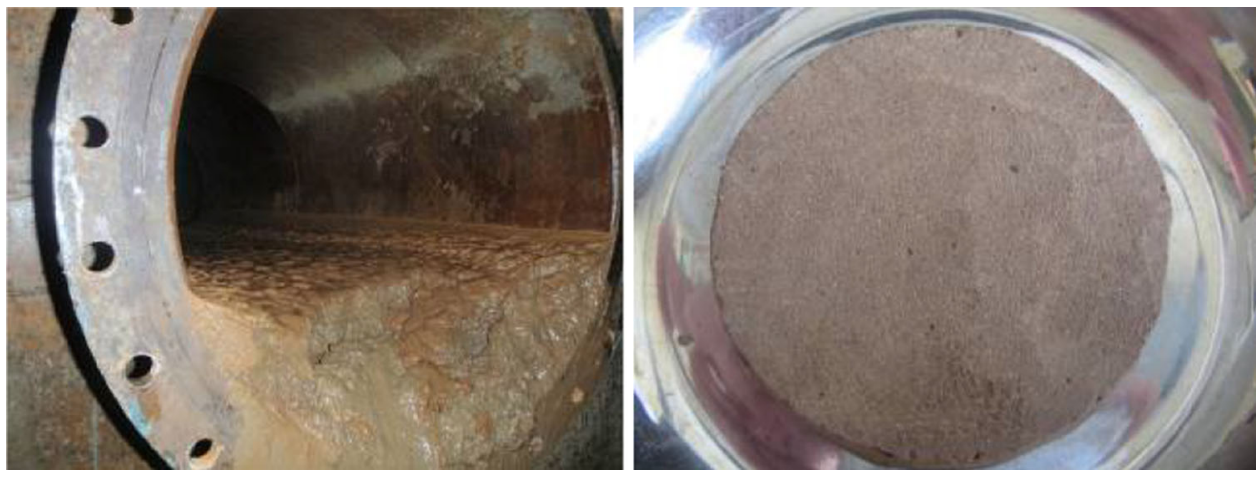
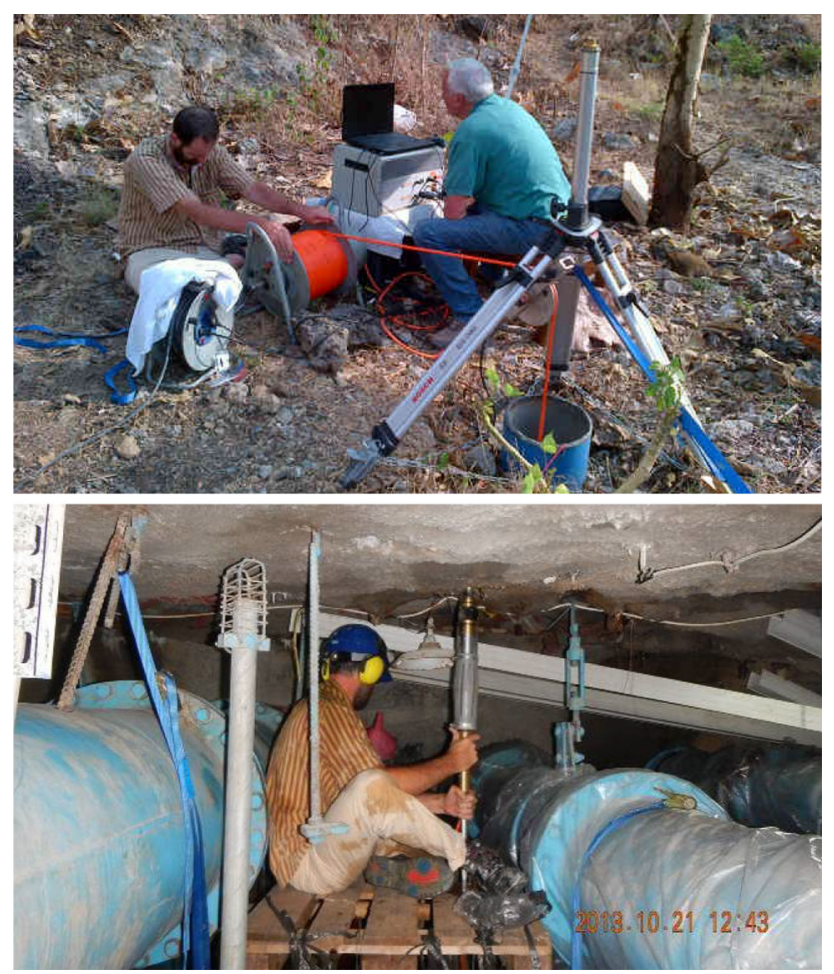

Fig. 9 Borehole camera in use on ground surface and at the cave roof

- Particularly in a zone 4-7 $\mathrm{m}$ above the cave roof, high permeabilities are to be expected due to wide crack openings and cavities.
- Due to horizontal joints and karst propagation, rock mass permeabilities are highly anisotropic. Pump tests in individual boreholes may depend on local boundary conditions and may not deliver a representative permeability for a larger system.

- Clayey coatings are prevalent. The unevenness of bedding joints and the tortuosity of karst hoses creates a high retention volume both for fine sediments (these are further deposited and eroded) as well as for the seepage water.

- A complete and permanent sealing of the karstified rock mass is unrealistic; however, grouting measures are locally effective and can be repeated depending on the observed mobile clayey void fillings which tend to occur during resp. after hydraulic breakthroughs.

- Water pressure built-up behind zones of low permeability must be prevented by effective drainage. Particularly, the system of drainage holes (Fig. 6) in the roof must be maintained and kept in good shape.

\section{Injection curtain}

First reservoir tests in 2008 with maximum hydraulic heads of 16.8-19.5 m showed $12.5 \mathrm{l} / \mathrm{min}$ resp. $23.3 \mathrm{l} / \mathrm{min}$ of seepage water (Mutschler and Triantafyllidis 2009). Although the safety of the barrage and the surrounding rock was not endangered, serviceability concerns led to 


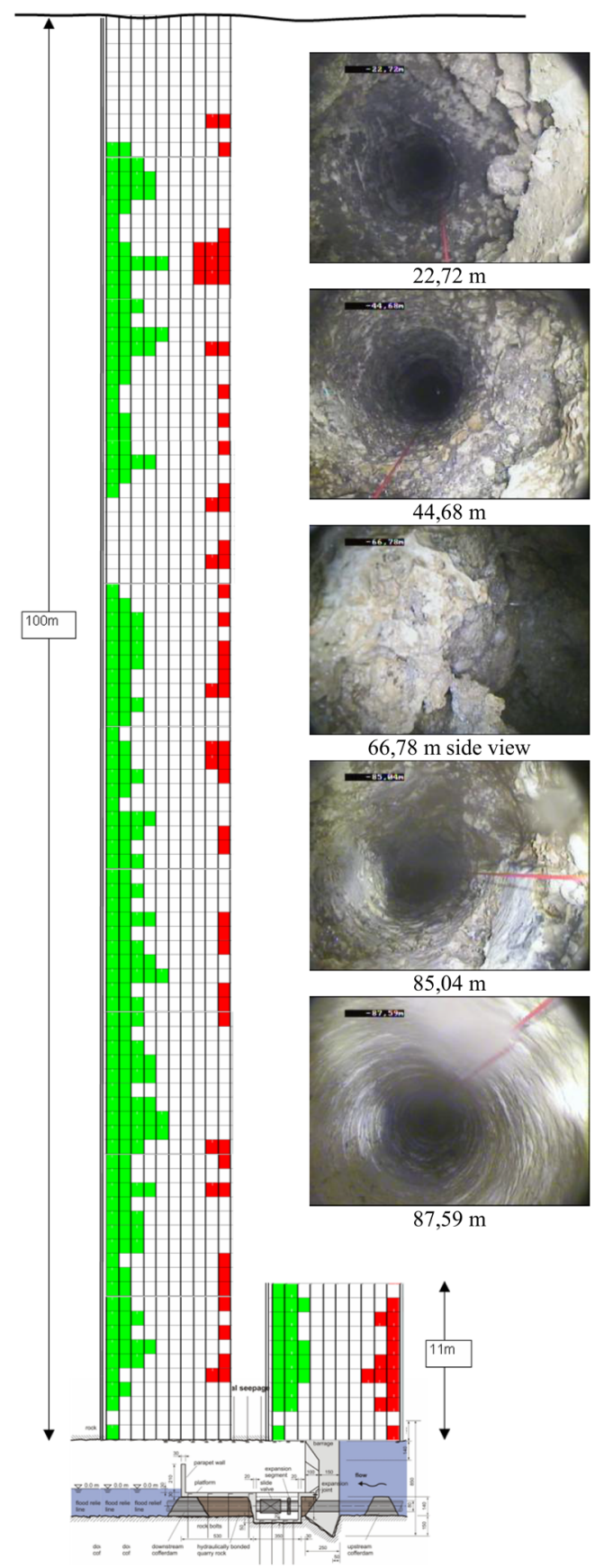

Fig. 10 Borehole camera report above cave with snapshots

the conviction that an additional fan-shaped grout curtain is required (recommendations for the installation of an injection curtain from 2008 reported in (Kudella and Loges 2014)). With regard to the maximum operational head of $15 \mathrm{~m}$ (the barrage design head was $30 \mathrm{~m}$ ), the curtain was designed to reach out to the same height, $15 \mathrm{~m}$ from the barrage structure into the limestone rocks (Fig. 11). It was realized in three subsequent grouting campaigns.

\section{First grouting campaign}

As the feasibility was still uncertain at the beginning, a test injection was discussed with the Indonesian side and carried out in 2009. In the leak zone between access shaft and barrage consisting of different materials from compact limestone to breccia, two injection boreholes were drilled and filled with cement grout using a single packer. A control borehole in between showed that the grout has a flow reach of 1-1.5 m under applied pressures of $10 \mathrm{bar}$, i.e. the cavernous rock mass was groutable with the standard equipment available from local contractors. More sophisticated suggestions as the hydraulic prospection of clay fillings using water jets, the metre-wise determination of local permeabilities using double packers or the subsequent application of grouts with different viscosities were discussed but not yet carried out.

Subsequently, 21 fan-shaped arranged grouting holes were drilled with $56 \mathrm{~mm}$ diametre, $15 \mathrm{~m}$ length and $15^{\circ}$ incline against the flow direction (blue in Fig. 11). About 60 tons of cement resp. $92 \mathrm{~m}^{3}$ of grout (water cement ratio 1.2) were injected with pressures between 10 and 15 bar. The grout take was in the range of 3.0-6.8 $\mathrm{m}^{3}$ per hole, an overall average of $255 \mathrm{l} / \mathrm{m}$. Details of design, materials and execution of the grout curtain are given in Breiner et al. (2011).

The experiences in the first injection campaign show that an execution of the injection works in an underground karst cave located remotely in developing country is very demanding works and could require many short notice adaptations. For example, adaptation to use at that time available coarse-grained PPC cement instead of OPC cement which from a geotechnical point of view was not optimal, because the slurry cannot propagate properly into small fissures. Another concern is the limitation of the know-hows which leads, among others, to uncertainty to the following working procedure. For example during the injections, the 19 of 26 existing drainage holes were not flushed consequently and blocked with grout thereafter. So additional work was required either to reopen these holes to a depth of $6 \mathrm{~m}$ with a diametre of $56 \mathrm{~mm}$ or drilled further new drainage holes to replace those which had become inaccessible by the installation of HPP piping system.

\section{Second grouting campaign}

After several reservoir filling tests which followed the first injection campaign, the seepage water had diminished to $3-12 \mathrm{l} / \mathrm{min}$ with an average of only $6 \mathrm{l} / \mathrm{min}$. Nevertheless, remaining gaps are unavoidable in a fan-shaped injection curtain with limited grout propagation. These gaps were assumed to be responsible for the fact that the seepage discharged mainly occurred from 7 distinct drainage spots. 
Fig. 11 Cross section of the grout curtain (coloured: the 3 injection campaigns)

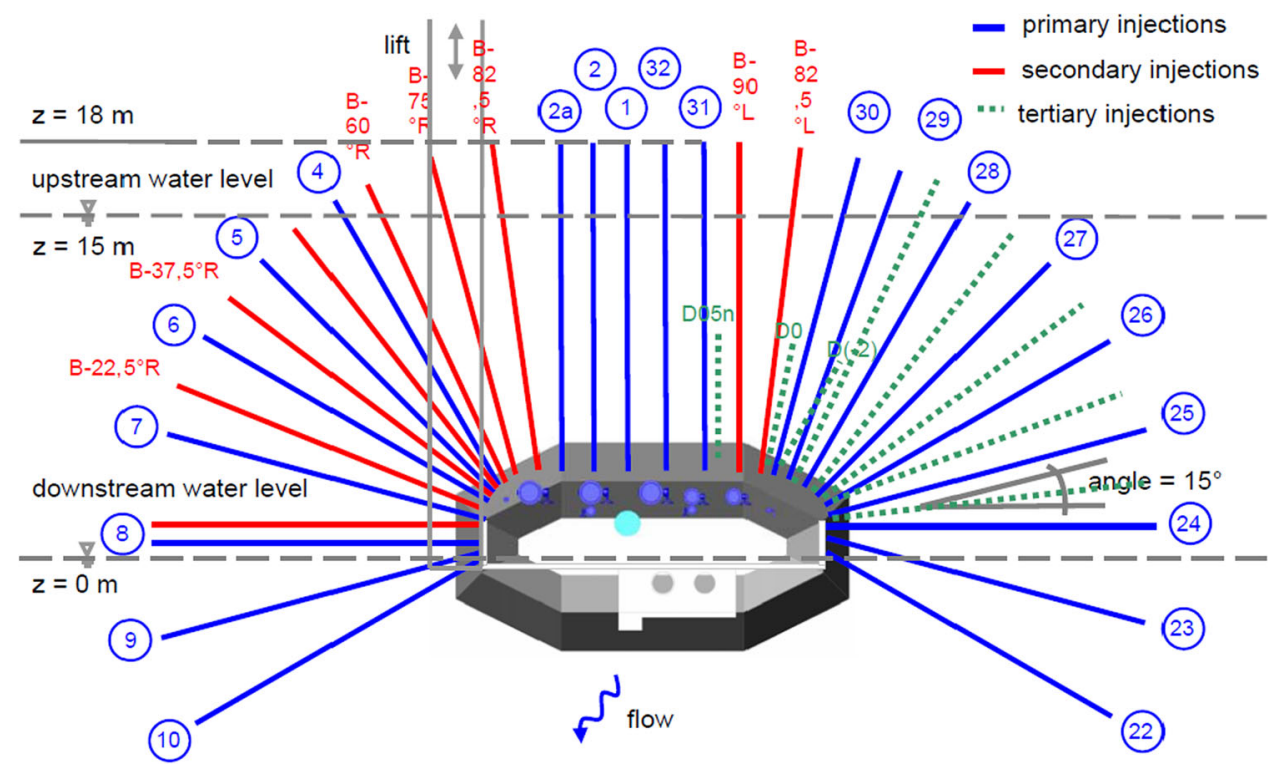

Therefore, a second grouting campaign was proposed and realized 1 year after the first campaign. Prior to this second campaign, a systematic review of all drainage holes was carried out (Breiner et al. 2011). This time, 3.6 tons of OPC cement resp. $5.2 \mathrm{~m}^{3}$ of grout were needed for 9 additional injection holes (marked red in Fig. 11). OPC cement with a higher grinding fineness could be provided this time which is suitable to close remaining narrow flow paths. On one hand, the rock mass was already partially sealed by the previous campaign. On the other hand, during the second campaign grouting of a borehole section had to be stopped more frequently because hydraulic connections appeared between neighbouring boreholes due to the dense drilling grid. Both factors may have contributed to a grout take seven times smaller than during the first campaign.

During the 1st year after the secondary grouting, optimism prevailed that bypassing of the barrage had been reduced by as much as $95 \%$ (Breiner et al. 2011). During this time, the plant was only temporarily operated resp. the underground reservoir was filled only occasionally. After the plant's commissioning for continuous operation, however, it became clear that the seepage behaviour of the system had in fact been improved less. Since 2011, as the HPP was in permanent operation, this could be observed better than before because also the seepage water monitoring was accomplished continuously. Repeatedly, hydraulic events attracted attention characterized by a sudden decrease of hydraulic flow resistance and sudden increase of seepage. In this article, they are called "hydraulic breakthroughs".

A first event of this kind had been observed in 2008 and was traced back to vibrations caused by cavitational effects in an HPP valve (Mutschler and Triantafyllidis 2009). It was thought that these vibrations could have reduced the shear strength of the clayey fillings and the critical hydraulic gradient. But as such events repeatedly appeared also seasonal effects were discussed besides dynamic triggers. These seasonal effects can be described as a cyclic alternation of sedimentation and erosion of the clayey cavity fillings. With rising water level, these deposits become inundated, pressurized by a local hydraulic gradient, and-after a continuous flow path has formedwashed out by retrograde erosion. Cyclic changes of the fillings' consistency and shear strength may also play a role even, though a complete dryout of the karst is not expected. The understanding is that the occurrence of hydraulic breakthroughs could be triggered either by sudden pressure changes or dynamic events.

\section{Third grouting campaign}

After the second injection campaign, almost $75 \%$ of the bypassing water precipitated from two drainage holes dewatering the breccia at the left wall side (in flow direction). Aiming to improve this situation, a third prophylactic grouting campaign was carried out in 2013 [reported (Kudella and Loges 2014)]. Here, the amount of 3.0 tons of PPC cement resp. $5.1 \mathrm{~m}^{3}$ of grout was injected into additional 5 injection holes (green in Fig. 11). As in the first and second campaign, the grouting pressure was limited to 12 bars to avoid fracturing. Nevertheless, the grout take of $68 \mathrm{l} / \mathrm{m}$ exceeded the value of the second campaign by a factor 2 (Fig. 12). In the first grouting steps, working pressures as low as 0.5 bars were sufficient for a considerable grout take. Obviously, there was still a considerable void volume

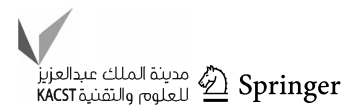


remaining — or made available again after some years of hydraulic loading-which could be filled.

The drainage holes themselves were not closed, because in the 1 st weeks after the campaign the system seemed to be much better tightened than ever before with discharges below $2 \mathrm{l} / \mathrm{min}$ also during reservoir filling resp. plant operation. However, this first optimistic impression changed again during flood events a few months later (Fig. 13), although the mean seepage value remained on an acceptable level of $9 \mathrm{l} / \mathrm{min}$. It is striking that this chronology had been similar after the first and second injection campaign. Until now, the period under observation is not sufficient to quantify a 'natural' untightening effect during rainy seasons and an eventually corresponding tightening effect during dry seasons. However, these effects are currently assumed to be a potential explanation for the systems behaviour resp. the occurrence of varying amounts of seepage water.

\section{Automated seepage monitoring}

The automated monitoring system was installed in 2011 and allows a better identification and interpretation of the variability of hydraulic appearances and the enhancing effect of the grouting campaigns mentioned before. The automated monitoring system collects the seepage water from 30 leaks via a system of channels installed at the roof of the cave (Fig. 14). The water flows to a measuring container downstream of the parapet wall where it discharges over three outlets in different heights. A pressure gauge controls the water level in the container and

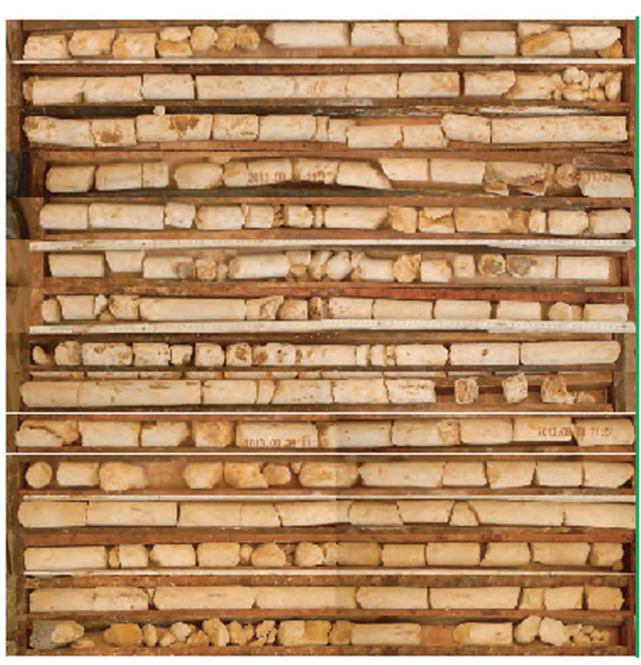

$0 \quad[$ liter/m] 140

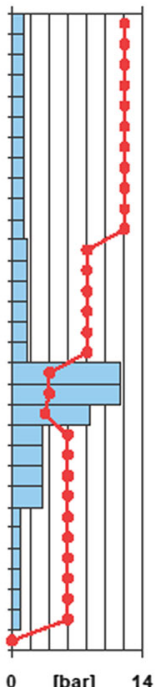

Fig. 12 Injection borehole core 7, $5 \mathrm{~L}$ compared to grouting pressure and grout take (third injection campaign)

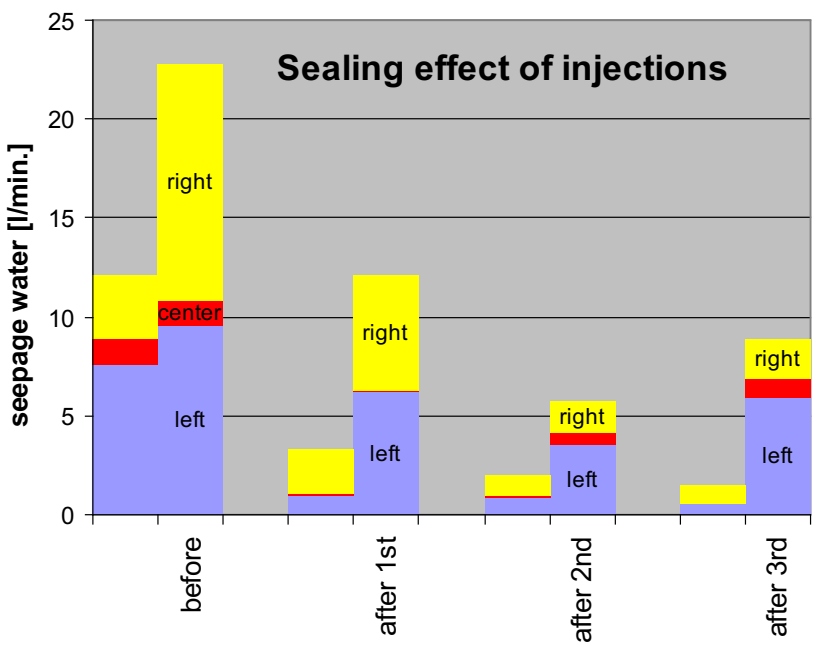

Fig. 13 Reduction of bypassing water from right, left and center seepage area, left column: minimum, right column: mean value

calculates the discharge from the three individual discharge relations. The signals are transferred to ground surface and registered together with the storage level inside the reservoir (difference between upstream and downstream water level) and HPP discharge.

Of course not the complete bypass water is recorded. Portions passing under the platform, parallel to the cave axis or along "detours" to downstream outlets at the cave wall cannot be precisely identified. The seepage portions attributed to the left, right and center parts of the cave in Figs. 13 and 15 are not measured continuously, but are extrapolations from the spatial manual measurements.

The measuring container has two measuring limits: For small seepage discharge $Q<1.6 \mathrm{l} / \mathrm{min}$ as well as for high values $Q>20.6 \mathrm{l} / \mathrm{min}$, the measurement data are not valid. Mostly for well-controlled operational conditions and

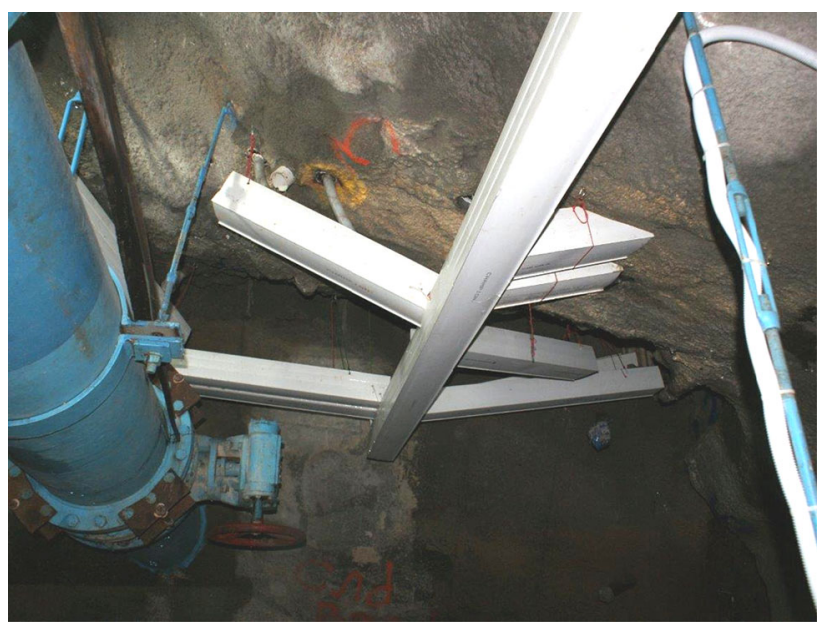

Fig. 14 Seepage water catchment for automated seepage monitoring 

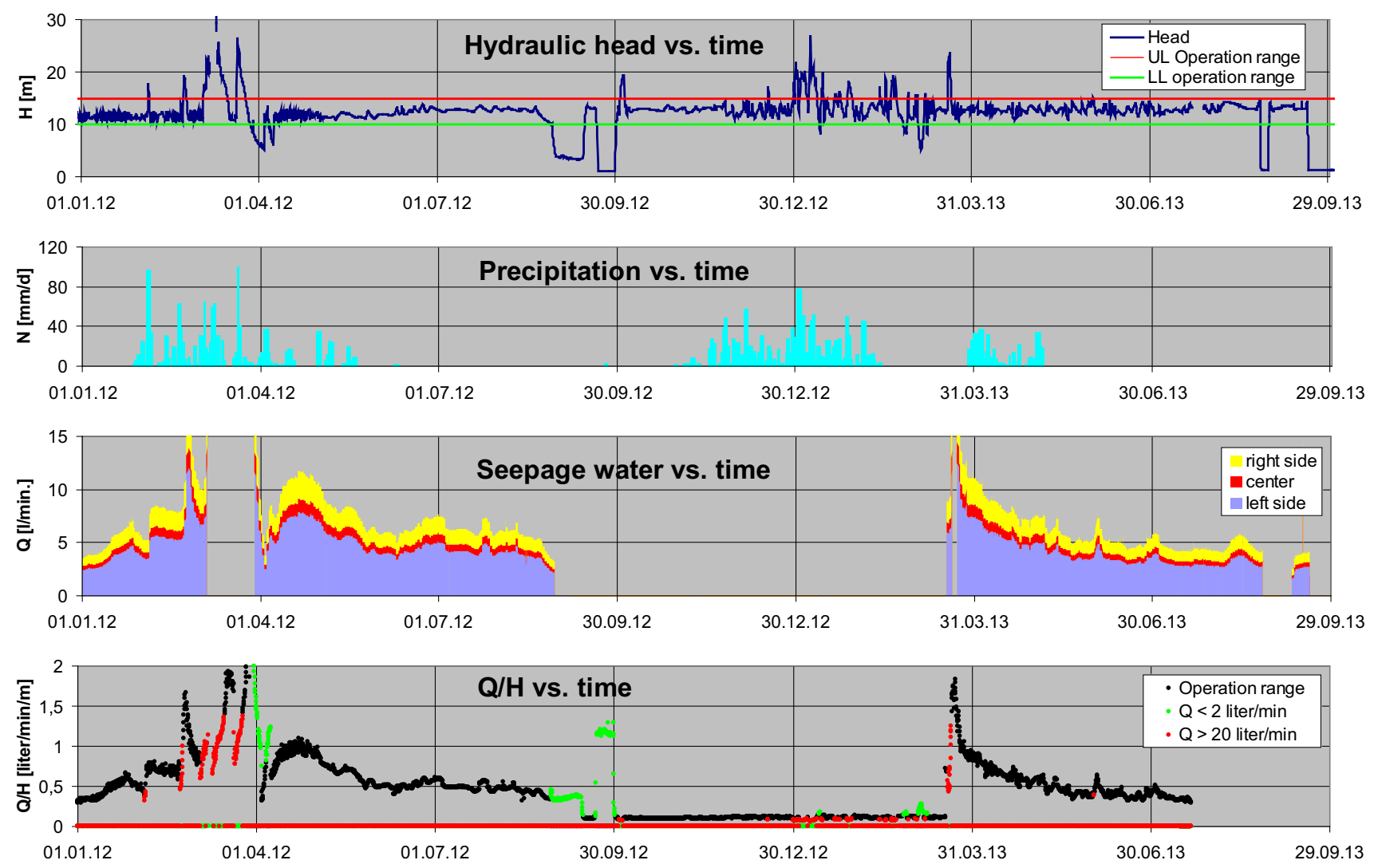

Fig. 15 Seepage monitoring data including rainfall and Q/H evaluation over 21 consecutive months

short-term flood events, the discharge remains between these limits. Due to these out-of-range phases, as well as due to downtimes of the automated monitoring system for other reasons, only $45 \%$ of the total time could be evaluated.

The upper measuring limit is regularly exceeded when the HPP is not adjusted fast enough to a sudden flood event; in this case, the reservoir storage level exceeds the operational range (10-15 m) and, consequently, overflows the grout curtain. Presumably under such conditions, hydraulic breakthroughs appear which transfer the geohydraulic system to a completely new stage. If no continuous record is available, only the changed system tightness can be identified by hindsight. It seems that such breakthroughs happened after each grouting campaign until now.

\section{Seepage record interpretation}

The quantity and distribution of seepage water have now been monitored over 6 consecutive years. As a careful evaluation of seepage, hydraulic head and precipitation monitoring shows that seepage depends on many factors besides the hydraulic head inside the reservoir. This can be shown by plotting hydraulic heads and bypassing discharge over time. A quotient $Q /$ h (amount of seepage water divided by hydraulic head) was introduced as a measure for the relative change of the overall rock mass permeability (Fig. 15). $Q /$ h should remain approximately constant as long as the permeabilities and hydraulic boundaries in the system remain unchanged. This, however, is not the case and demonstrates that the flow conditions change with time.

Precipitation measurements (supplied by the hydrological project partner and given as daily total) from the three closest meteorological stations were incorporated in the representation to quantify correlations with rainfall. The precipitation assumed for Bribin is the mean value of maximum and minimum of the three stations. Time delays result from cross-correlations. Findings are:

- Individual short rain events have only minor influence on seepage. But continuous heavy precipitation triggers flood waves in the cave aquifer with a typical time delay of 2-3 days. Local experts report a time delay of 6-8 h only, maybe rather by direct discharge into the cave stream than by percolation.

- Hydraulic heads exceeding $15 \mathrm{~m}$-no matter whether due to a flood event or control disorder-cause higher bypass volumes. Flow paths closed by sediments are 
subsequently flushed which leads to an increase of the system permeability (a factor 2-3 was observed so far but this may need correction in the future, so further investigation is recommended).

- This increase of system permeability causes a high bypassing with a further time delay of 1-2 days referring to the flood event.

- Should the overtopping situation remain or be repeated within a few days, bypassing remains at levels exceeding the measurement limit of $20 \mathrm{l} / \mathrm{min}$ (therefore, the measurement limit will be increased in the near future).

- When the rain stops and the overtopping situation ends, bypassing decreases exponentially over a few months.

- Dry periods lead to a successive draining of the rock mass, possibly also to a self-tightening of the flow system with a permeability decrease (the factor could again be 2-3; however, this is subject to future observations).

Tracer tests, reported later in this paper, speak in favour of a combination of different time scales of the wateringdewatering effects: one between hours and days and a longtime effect over months. A further distribution of the total discharge, based on the manual measurements, shows that the portion leaking from the left side (in flow direction) is variable, while the right and center zone are most widely constant.

Due to the roughness of bedding joints and the tortuosity of karst voids, the rock mass contains many depressions where fine sediments are deposited (Fig. 16). After dry seasons, the karst aquifer seems to be sealed by finegrained sediments closing most flow paths. These fillings are dissolving resp. eroded under a new inundation and steady action of hydraulic gradients. Repeated flood events during rainy seasons erode the fillings and create cascades of local "hydraulic breakthroughs" with the consequence of increasing seepage. This effect is amplified when a sudden increase of hydraulic head exceeds the operational

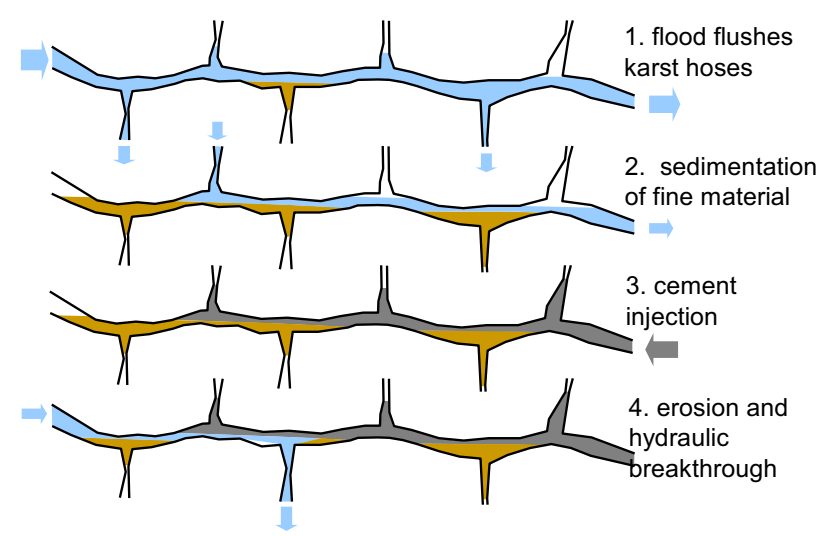

Fig. 16 Schematic sedimentation and breakthrough model range and the grout curtain is temporary overtopped. The system permeability, thus, changes distinctly between dry and wet seasons (Fig. 16).

As assumed by geotechnical experts from the very beginning, an entire and durable tightening of the rock mass by injection measures is not applicable. However, considerable improvements were achieved with the second and third grouting campaign, although the obtained sealing effect by each campaign is not completely sustainable. Frequent injection campaigns probably cannot optimize the rock mass beyond a certain point (Fig. 13). Accordingly, a permanent sealing of the karst flow requires different strategies explained later.

\section{Observation-based permeability analysis}

The input parameters for numerical models using finite elements or differences can easily be "calibrated" to deliver measured hydraulic heads or seepage volumes at hindsight. For Gua Bribin, the ambitious attempt was made to forecast the hydraulic behaviour using a parameter determination exclusively based on field investigations.

The analytical method proposed by (Oda 1985) calculates the anisotropic permeability tensor of a discontinuous porous rock mass from the characteristic cavity distribution and geometry, i.e. commonly joint orientation $(n)$, width of joint opening $(t)$, joint length $(r)$ and number of openings $\left(m_{\mathrm{c}}\right)$ in a reference volume $(V)$ :

$k_{i j}=\frac{g \times \lambda}{v \times V} \times \sum_{m=1}^{m_{\mathrm{c}}(V)} \frac{\pi r_{(m)}^{2} \times t_{(m)}^{3}}{4} \times\left(\delta_{i j}-n_{i}^{(m)} \times n_{j}^{(m)}\right)$

Hereby, $g$ is the gravity acceleration, $v$ is the kinematic viscosity and $\lambda$ is a dimensionless correction factor. Oda's leading imagination is an open penny-shaped crack or joint, intersected by a borehole. The only information which is not directly measured in the borehole is the crack extension in relation to the reference volume. As karst cavities usually are not penny-shaped, Moik (2014) extended Oda's formula by a second constituent for a tube-formed cavity representing $\left(m_{r}\right)$ propagating karst hoses of length $(h)$ and diametre $(d)$ :

$$
k_{i j}=\frac{g \times \lambda}{v \times V} \times\left[\begin{array}{c}
\sum_{m=1}^{m_{\mathrm{c}}(V)} \frac{\pi \times r_{(m)}^{2} \times t_{(m)}^{3}}{4} \cdot\left(\delta_{i j}-n_{i}^{(m)} \times n_{j}^{m}\right) \\
+\sum_{m=1}^{m_{\mathrm{r}}(V)} \frac{3 \times \pi \times h_{(m)} \times d_{(m)}^{4} \times n_{i}^{(m)} \times n_{j}^{(m)}}{32}
\end{array}\right]
$$

From the camera inspections of the vertical boreholes, the spatial distribution of joints and karst cavities could be 
determined accurately, their inclinations at least qualitatively. Most voids have a horizontal orientation which makes a relation of the scanned borehole wall against the north direction dispensable. Opening widths could be determined from the horizontal borehole scan. The procedure assumes that all this information is also representative for the "hidden" part of the rock mass and can be generalized for the whole continuum.

Theoretically, the same information content should be given by the drill cores. In practise, this is not the case, however. Breaks in cores may have occurred due to preexisting cracks or due to mechanical overstraining. The drill cores in the core box may not still have their original orientation or sequence, particularly when the geological situation caused a poor core recovery. Anyway, the video records proved much more reliable, but still the evaluation was rather demanding.

As the first evaluations of generalized Oda's formula were made, some further shortcomings of the method became evident:

- The void and crack distribution in some distance from the borehole is unknown and assumed equivalent to the known borehole: The crack or hose extension must be assumed.

- Pressure dissipation in the flow paths is generally underestimated, because the hydraulic wall roughness is neglected. An empirical correction factor is employed for this $(\lambda)$.

- The opening width is only known at the void entrance at the borehole wall; the hydraulically governing width may be quite smaller and located elsewhere. As errors in the width propagate to permeability with the third/forth power, a further arbitrary correction factor $d$ must be applied and dominates the results for $k$.

- Smaller crack systems which are not visible in the graphical documents require a second, isotropic or anisotropic matrix permeability delivering a non-zero "background value". To estimate this, the visual roughness of the borehole wall was classified in five arbitrary grades and taken as reference.

- The procedure, when applied to a layered rock mass, may not necessarily lead to "characteristic" permeability values for the different geological units.

To summarize the experience with this method: if the critical correction factors shall not again be "calibrated" with measurements, the information density required from borehole scans is higher than usually available, because it must also represent the surrounding volume. This reduces the practical benefit of the method considerably.

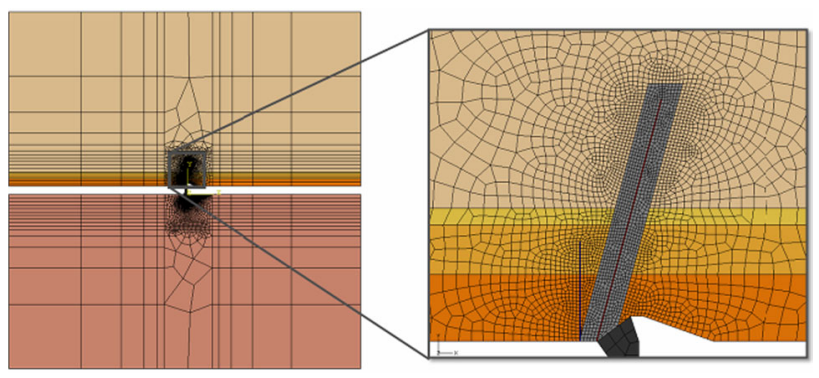

Fig. 17 FE mesh for the 2D model, left: cave and barrage, right: detail with grout curtain

\section{Numerical seepage modelling}

The underlying questions of these studies are whether the measured seepage can at least qualitatively be predicted either using measured field permeabilities or data generated using analytical formula. The scientific FE code ABAQUS/ Standard was used for this modelling. It incorporates the iterative time integration of a two-phase solid-fluid-analysis, in which Terzaghi's effective stress principle holds and total stresses are defined as sum of effective stresses and hydrostatic pore water pressure. For the 2D model, plain quadrilinear CPE4P elements and for the 3D model, tetrahedral 10-node C3D10MP elements were used. Derived results are seepage velocities and flows, while solid phase displacements and pore pressures are the primary nodal unknowns.

\section{D model}

To study basic relations, a plain-strain 2D model representing the longitudinal section of Bribin cave seemed already sufficient. For simplicity, cave roof and floor were assumed to be parallel (Fig. 17). The simulation was made for a 10-week period in spring 2013 subdivided into 569 "time frames" for which pressure head as well as seepage data were complete including one flood event of $Q>20 \mathrm{l} /$ min. The following boundary conditions were applied:

- A time-dependent hydraulic pressure $(p)$ according to the measured head applied to the upstream cave wall.

- Zero-pressure outflow at the downstream cave walls and drainage holes.

- Precipitation $\mathrm{q}(\mathrm{t})$ as inflow on ground surface seeping away in vertical direction.

- The rock mass was assumed to be impermeable with $1 \mathrm{~m}$ radius around the injection curtain.

- Disregard of solid phase displacements.

As parameter studies show that an equivalent isotropic rock mass permeability of $k=2.2 \times 10^{-5} \mathrm{~m} / \mathrm{s}$ is required to explain the measured seepage volume (Fig. 18). The 

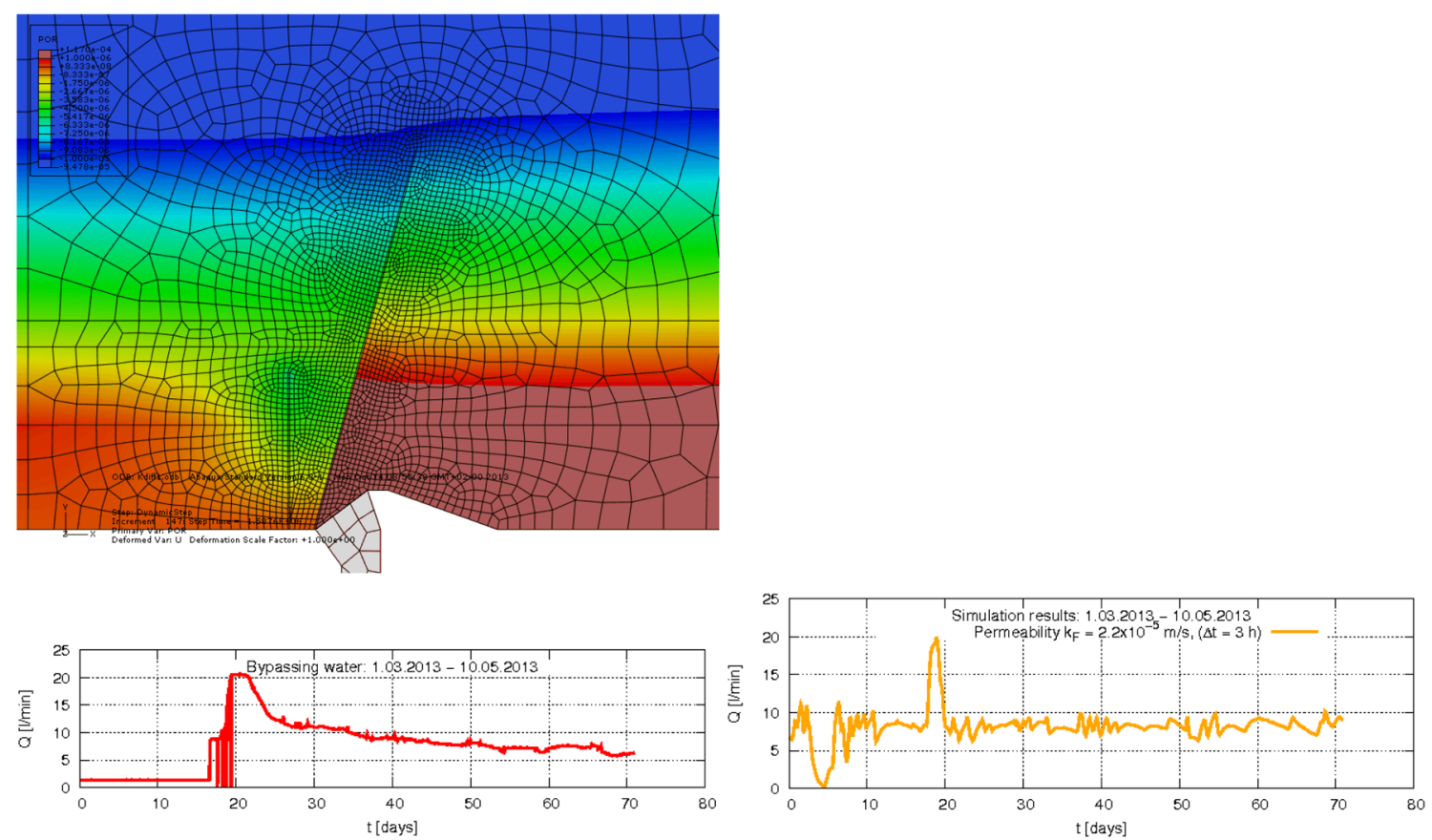

Fig. 18 Top: calculated porewater pressure distribution for hydraulic head of $22.5 \mathrm{~m}$, bottom: comparison of bypassing water over a 50 -day period, top: measured, bottom: calculated for $k=2.2 \times 10^{-5} \mathrm{~m} / \mathrm{s}$

anisotropic permeability results as $k=3 \times 10^{-5} \mathrm{~m} / \mathrm{s}$ in horizontal and $k=1 \times 10^{-5} \mathrm{~m} / \mathrm{s}$ in vertical direction, accordingly. However, if the overlying $12 \mathrm{~m}$ of rock, subdivided into 4 layers, is modelled with the permeabilities determined from in situ borehole pump tests, the measured seepage is underestimated by a factor of 30 . Furthermore, the influence of precipitation is also small in the numerical study and can in most cases be neglected in such flow models.

Tentatively, a sorption law was employed to model the time delay between hydraulic head changes and seepage fluctuation. This is possible principally, although there is no well-founded procedure how to determine the parameters for such a transient model. The applicability of the available data for this has not been evaluated yet.

\section{D model}

As the 2D model cannot quantify the lateral bypassing around the barrage and the grout curtain as well as other special effects, also a 3D model was developed (Kaltenbach 2014). Concrete barrage and fan-shaped grout curtain are now modelled according to their three-dimensional geometry. Other 3D effects were simplified; for example, the varying permeability due to the variable injection hole distance and the exact direction of the 27 active drainage holes in space (Fig. 19).
Applying the undeformed 3D model, the measured seepage is approximated by an equivalent isotropic rock mass permeability of $k=5 \times 10^{-5} \mathrm{~m} / \mathrm{s}$. In accordance with observations, outflow concentrates on the side drainages and seepage peaks are more pronounced. Including solid phase displacements, the equivalent isotropic rock mass permeability is lowered to $k=1.6 \times 10^{-6} \mathrm{~m} / \mathrm{s}$ which is at least within the range of the in situ tests for highly karstic layers. The hydro-mechanical coupling also brings out inundation and dewatering effects with the related time delays, at least qualitatively. This does of course not include sedimentation and erosion effects. Due to the Finite Element Method (FEM) study, the deformations grow proportionally with extreme hydraulic heads in the range of 10-45 m, but these results are questionable due to the assumed linear elasticity of the rock mass. The calculated deformation (convergence) of the cave walls is negligible under operation conditions.

\section{Hydrochemistry and hydrochemical modelling of seepage water}

Assessing the stability of the HPP, one question has always been whether ongoing karstification could lead to a significant enlargement of the karst cavities. The hydrochemistry of seepage and Bribin river water was determined over a time period of 4 weeks to characterize their composition and possible interactions. Both river and 
Fig. 19 Top: FE mesh for the 3D model with calculated porewater pressure distribution, bottom: comparison of calculated bypass water with and without hydro-mechanical coupling for a 160 -h period
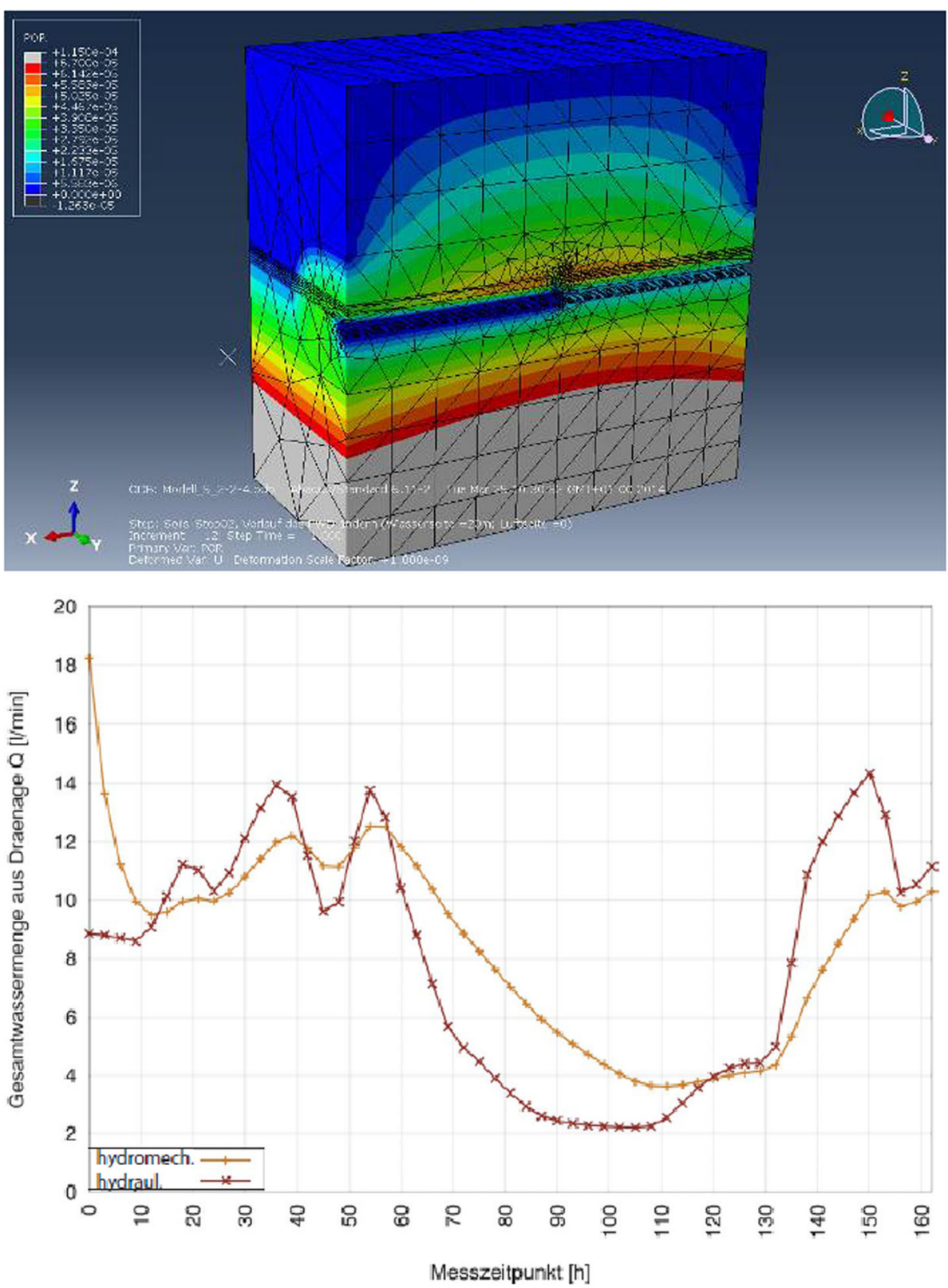

Based on the hydrochemistry, it is also possible to calculate the saturation of both types of water with regard to calcite. The results clearly show that river and seepage waters are intermittently subsaturated. This means that the water periodically has the potential to dissolve calcite and, consequently, that active karstification takes place. Hydrochemical modelling using the code PhreeqC indicates that, in an extreme case, up to $95 \mathrm{mg}$ calcite per litre could be dissolved by the seepage water during passage of the limestone assuming that full saturation takes place. This, however, is not expectable. Furthermore, most of the samples had a much lower subsaturation leading to lower amounts of calcite dissolution. that slowly infiltrating and percolating rain water, so-called matrix flow, additionally feeds the seepage water. seepage water are similar with regard to major cation $(\mathrm{Ca}$, posed of river water that continuously infiltrates into the overlying karst rocks in response to water storage. In pools. This is in accordance with the seepage record 
First indications on the flow dynamics of seepage water were gained by means of tracer tests using fluorescence dyes. The results indicate the existence of different flow regimes: (1) a quick component with residence times in the limestone in the range of hours to days. In this context, larger cracks and fissures are probably decisive; (2) a very slow matrix flow component with retention times of several months.

To estimate the extent of karstification, the results were combined in a 1D hydro-geochemical transport model using PhreeqC. The model was based on a potential crack with a diametre of $1 \mathrm{~cm}$ and a length of $50 \mathrm{~m}$. Two scenarios were considered differing mainly in the flow velocity and the discharge flowing through the karst. In case (A), the flow velocity was set to $10 \mathrm{~m} / \mathrm{h}$ and the discharge to $0.8 \mathrm{l} / \mathrm{h}$. The model predicts that along this crack the amount of limestone which will be dissolved is $0.64 \mathrm{~kg} /$ a. Increasing the flow velocity in case (B) to $50 \mathrm{~m} / \mathrm{h}$ leads to an increase of the amount of potentially dissolved calcite to $2.3 \mathrm{~kg} / \mathrm{a}$. This model, however, assumes that subsaturated Bribin river water is constantly available throughout the year which is not the case.

The indicated amount of calcite which might dissolve during 1 year, however, will not lead to severe impairment of the functionality of the hydropower plant during its assumed life span.

\section{Conclusions}

As shown for the example of Gua Bribin, combined investigation, monitoring and numeric models proved to be helpful to understand the seepage phenomena and quantities around underground barrages in karst rock. Monitoring, data acquisition and evaluation cannot be given as a fixed requirement, especially in geologically unique or partly unknown conditions. Rather are they part of a learning process reacting to progressing investigations and system behaviour. Structural interventions like grouting are also based on repeated learning and follow the "observational method". Effective water retention schemes with sufficient safety and serviceability can be established by this consequent way of learning. It is important that operating crew, local and external experts work together and complement one another with their knowledge.

Numerical models, even state-of-the-art, have difficulties to provide independent predictions, because input data are scarce and sometimes tentative. One main reason is that information about rock mass porosity and permeability was mainly based on information gained through borehole scans, therefore, only locally available. Borehole pump tests in individual boreholes and borehole camera inspections are valuable to distinguish layered properties and anisotropies. Particularly in karst, however, the line-information they provide may not be generalizable for the general rock mass properties.

Due to levelled bedding joints, the identification of the crack inventory was not so much a focus of the Bribin investigations. In different conditions, the use of Terrestrial Laser Scanning has proved its worth (Mutschler et al. 2014).

Geo-hydraulic evaluation tools like Oda's procedure of permeability determination contain arbitrary correction factors which shoot down their precision. Parameter variations in the numerical models, however, are still instructive, as they can limit the unknown quantities by comparison of the resulting seepage with the accomplished measurements.

A special challenge was the modelling of watering-dewatering effects and variable sediment permeability. Tools to approach these transient processes still have to be identified; the theory of partially saturated media may help.

Sophisticated model refinements, i.e. for the true cave geometry and other 3D details, do not pay as long as applied permeabilities are not realistic or do not fit basic measurements. If such high-level models are planned (which originally was not the case for Bribin), the monitoring concept should be extended as follows:

- A grid of level gauges measuring the hydraulic head in the rock mass in various distances from the barrage. Only one hydraulic head record cannot tell whether the reservoir as a whole acts as a hydraulic sink or source. Without this information, the models had to make the assumption that no water leaves the modelling area sideways.

- Additional piezometers and tensiometers could report in which periods one coherent water table exists and when clayey fillings dry out. However, after these instruments fell dry, their hydraulic coupling to the medium may get lost irreversibly.

- An inflow- and outflow balance of the total cave wall surface could be realized by upgrading a measuring weir in the upstream cave in addition to the downstream HPP flowmeter. As a precondition, the inflow-outflow difference must be large enough to be identified with the sufficient accuracy.

- Sedimentation and erosion of the clayey void fillings could be examined in an isolated in situ region or a representative "artificial" void system under different hydraulic heads and waiting times.

Seepage monitoring data over several years of operation were absolutely essential. From the past experiences, any improvements should focus on the monitoring system with regard to robustness, easy handling, training local users, maintenance and enlarging the measuring span to cope 
with extremes. During the first year of operation, the available data were the most important source of information to appraise the effectiveness of grouting.

Worldwide, there are very few examples of effectively sealed barrages or water retention schemes in karst areas. Following the experience, conventional injection strategies may fail to seal the flow paths sustainably without a systematic pre-treatment. Such pre-treatment may be the systematic flushing of karst voids using water jets in a close-spaced grid of boreholes. Its aim must be that the grout encounters an "empty" pore system rather than a system partially filled with highly mobile constituents. An alternative is the construction of continuous sealing walls (like diaphragm panels) down from the ground surface. Compared with the present design, both alternatives would require a much higher effort in terms of time and costs. For the existing Gua Bribin barrage, the residual amount of bypassing water $(6-10 \mathrm{l} / \mathrm{min})$ roughly equals $0.4 \%$ of the HPP's design output and can, thus, be accepted. Compared to the amount of water used for energy generation by the PAT, this ratio is even distinctly smaller.

Therefore, a further continuation of monitoring has been strongly recommended as the HPP was handed over to the Indonesian representatives. It should comprise automated and manual seepage measurements, visual inspections, hydraulic pressure monitoring, convergence measurements and divers inspections, summarized in an annual inspection and evaluation report. Some observations are connected with alert criteria. Besides the maintenance of the monitoring equipment, future interventions may be needed including further injection campaigns. Their focus, however, is not a further tightening of the system, but to regain at least the present state of serviceability in case of future system deterioration. But future monitoring could also bring to light at long sight that the system improves by natural effects or it further on cycles with the seasons between recurring states of tightness.

\footnotetext{
Acknowledgments The authors wish to thank the German Federal Ministry of Education and Research (BMBF) for the support of the IWRM-Indonesia joint research project, Sub-project 4: "Geotechnical aspects in the short-run and long-term behaviour of karst rock pressurized by subsurface water retaining structures (02WM0880)" between 2008 and 2014.
}

Open Access This article is distributed under the terms of the Creative Commons Attribution 4.0 International License (http:// creativecommons.org/licenses/by/4.0/), which permits unrestricted use, distribution, and reproduction in any medium, provided you give appropriate credit to the original author(s) and the source, provide a link to the Creative Commons license, and indicate if changes were made.

\section{References}

Breiner R, Bohner E, Fenchel M, Müller HS, Mutschler Th, Triantafyllidis Th (2011) Grouting of an underground concrete barrage in Karst limestone, Asian trans-disciplinary Karst conference 7, Yogyakarta, Indonesia, 10 Jan 2011

Kaltenbach M (2014) Hydromechanische Modellierung von Gebirge in der Umgebung von unterirdischen druckwasserhaltenden Absperrbauwerken. Diploma thesis at IBF, Karlsruhe Institute of Technology

Kudella P, Loges I, Triantafyllidis Th (2014) Abschlussbericht 02WM0880, Verbundprojekt Integriertes WasserressourcenManagement (IWRM) in Gunung Kidul, Java, Indonesien, Teilvorhaben TP 4 Kurz- und Langzeitverhalten von Karstgebirge in der Umgebung von unterirdischen druckwasserhaltenden Absperrbauwerken. Available from TIB Hannover

Moik T (2014) Durchlässigkeit von geklüfteten und verkarsteten Felsmassen. Bachelor thesis at IBF, Karlsruhe Institute of Technology

Müller HS, Fenchel M, Bohner E, Mutschler T (2008) Bau eines Höhlenkraftwerkes zur Trinkwassergewinnung auf Java, Teil 2: Konzeption und Realisierung des Sperrwerkes unter Berücksichtigung örtlich verfügbarer Baustoffe und Technologien, Symposium Baustoffe und Bauwerkserhaltung, Betonbauwerke im Untergrund-Infrastruktur für die Zukunft, Müller HS, Nolting U, Haist M (eds.): University of Karlsruhe Scientific Publishing, 121-137

Mutschler Th, Berner Z (2005) Report on site inspection of "Gua Bribin"-Project, Universität Karlsruhe (TH), 14-23 Oct 2005 cited in Kudella et al. 2014

Mutschler Th, Gröger D, Richter E (2014) TLS based determination of the orientation of discontinuities in karstic rock masses. In: Proceeding of XII. Int Congress IAEG, Springer-Verlag, Turin, 15-19 Sept 2014

Mutschler Th, Triantafyllidis Th (2009) Geotechnische Aspekte beim Bau einer unterirdischen Staumauer in verkarsteten Riffkalken. Wasserwirtschaft 99, Springer Verlag, 7-8:53-59

Nestmann F, Oberle P, Ikhwan M, Stoffel D (2012) Experiences concerning the implementation of innovative technologies and management strategies in emerging Countries: Example IWRM Indonesia. Proceedings of the IWRM Karlsruhe 2012, Karlsruhe, 21-22 Nov 2012, Fraunhofer Verlag, Stuttgart, pp 41-53

Oda M (1985) Permeability tensor for discontinuous rock masses. Geotechnique 4:483-495 